Canadian Oncology

Nursing Journal

Revue canadienne

de soins infirmiers

en oncologie

Volume 28, Issue 2 • Spring 2018

elSSN: 2368-8076 


\title{
E-health tools in oncology nursing: Perceptions of nurses and contributions to patient care and advanced practice
}

\author{
by Garnet J. Lau and Carmen G. Loiselle
}

\begin{abstract}
As oncology nurses confront a rapidly evolving field with increased workplace pressure, the integration of evidence-based connected health platforms within practice presents promise. This study explores nurses' perceptions regarding the utility of e-health tools, with a focus on the Oncology Interactive Navigator $\left(O I N^{T M}\right)$, as a potential contributor to their practice and interactions with patients. Focus groups with oncology nurses were conducted at two time points: prior to exposure to the $\operatorname{OIN}^{T M}(T 1, n=8)$ and four weeks post unrestricted tool access (T2, $n=7)$. Using qualitative constant comparison analysis, three themes emerged: (1) Key factors driving e-health use are multidimensional and evolving; (2) Dual role of e-health in meeting patient needs and supporting practice; (3) E-health as a catalyst for professional development and networking. E-health is appealing to oncology nurses, as it serves to advance practice and support patient care. Future research should explore best practices for optimal clinical implementation among all stakeholders involved.
\end{abstract}

Key words: oncology, nursing, e-health, connected health, internet, Oncology Interactive Navigator

$\mathbf{R}$ esearch suggests that oncology nurses continue to report inadequate organizational structures and training resources to support their ongoing professional development (Bakker et al., 2013; Lemonde \& Payman, 2015). High-volume work environments, inflexible work schedules, and limited resources have been cited by oncology nurses as barriers to meeting professional training requirements (Bakker et al., 2013; Lemonde \& Payman, 2015; Rennie \& Mackenzie, 2010; Santos, 2012; Schweitzer \& Krassa, 2010). Even though connected health, which includes electronic (e)-health and mobile (m)-health, has been found to offer support to oncology nurses in their practice, little is known on their perceptions of these

\section{ABOUT THE AUTHORS}

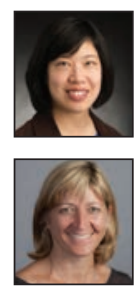

Garnet J. Lau, Ingram School of Nursing, McGill University; Garnet Lau is now at Clinical Research Program, Jewish General Hospital

Carmen G. Loiselle, Department of Oncology and Ingram School of Nursing, McGill University and Hope \& Cope, Lady Davis Institute, and Segal Cancer Centre, Jewish General Hospital.

Address for correspondence: Garnet Lau, Clinical Research Program, Jewish General Hospital, Montreal, QC H3T 1E2

Email: garnet.lau@mail.mcgill.ca

DOI:10.5737/23688076282118124 tools for the purpose of professional development and patient education. This study begins to explore the perceptions of nurses who are exposed to the Oncology Interactive Navigator $\left(\mathrm{OIN}^{\mathrm{TM}}\right)$ - a large repository of web-based person-centred cancer information, support, and health care service guidance.

\section{CONNECTED HEALTH: E-HEALTH AND M-HEALTH IN CANCER CARE}

The availability of various forms of connected health is a promising trend for health professionals, patients, and caregivers alike (Hesse, Greenberg, \& Rutten, 2016; Kaltenbaugh et al., 2015; Moule, Pollard, Armoogum, \& Messer, 2015). A survey of 179 oncology nurses indicated that important features of "favourite" connected health resources were: easy to read, disease and patient-focused information, and multimedia content (Jones, Schilling, \& Pesut, 2011). Connected health resources were more convenient, flexible, available, and accessible, when compared to traditional methods of professional development (Gilmour, Strong, Chan, Hanna, \& Huntington, 2016; Klemp, Frazier, Glennon, Trunecek, \& Irwin, 2011; Pilcher \& Bedford, 2011). However, nurses reported several drawbacks when using connected health resources. These included: limited experience and low self-confidence with new and evolving technologies; navigation that is not userfriendly; workplaces that are unsupportive or have poor access; and retrieved health information that may not be appropriate or up-to-date (Chiu \& Tsai, 2014; Gilmour et al., 2016; Jones et al., 2011; Santos, 2012; Verhoeven, Steehouder, Hendrix, \& van Gemert-Pijnen, 2010; Younger, 2010). Not surprisingly, health information technology has been better adopted when the user is provided with adequate training, feels confident, and is supported by colleagues or peers to use the system (Chiu \& Tsai, 2014; Hains, Ward, \& Pearson, 2012; Vedel et al., 2012).

The OIN ${ }^{\mathrm{TM}}$ is a Canadian e-health platform that provides key facts, tips, and guidance related to the cancer experience from diagnosis to survivorship. There are 14 OIN $^{\mathrm{TM}}$ titles, which each cover a different cancer diagnosis (e.g., bladder, blood, breast, colorectal, lung, melanoma, ovarian, prostate, thyroid). The platform is available in English with translation into French for some of the titles. As the colorectal cancer title is available in both official languages (i.e., French and English), it is a suitable connected health resource to examine in the Canadian setting of this study.

Although the OIN ${ }^{\mathrm{TM}}$ has typically been used by patients, nurses have found this resource to be most relevant to their practice and their patient education activities (Haase \& Loiselle, 2012). The OIN ${ }^{\mathrm{TM}}$ content was developed by a team 
of medical writers, editors, graphic designers, animators, etc. and is periodically reviewed by national and international cancer experts as well as supportive care personnel and patient representatives. Several studies have documented the various benefits of being exposed to the OIN ${ }^{\mathrm{TM}}$ (Dubois \& Loiselle, 2008; Loiselle, Edgar, Batist, Lu, \& Lauzier, 2010; Loiselle et al., 2013). In-depth and up-to-date information on treatments, side effects, and available patient resources, make the OIN ${ }^{\mathrm{TM}}$ an ideal resource for oncology nurses for supporting and educating patients in practice and for professional development. As health care professionals increasingly perceive internet-retrieved cancer information as adding value to the patient experience (Emond, de Groot, Wetzels, \& van Osch, 2013; Hains et al., 2012; Hauffman et al., 2016; Townsend et al., 2015), the attitudes and experiences of health professionals are critical considerations in the integration of new connected health technologies into practice settings. It is thus timely to further explore oncology nurses' perceptions of the potential promises and challenges related to these tools.

\section{STUDY PURPOSE}

This study explored the following questions: (1) What are oncology nurses' perceptions regarding the use of e-health in general? (2) How relevant is the OIN ${ }^{\mathrm{TM}}$ to their practice? (3) How can these resources contribute to patient care and nursing practice?

\begin{tabular}{|c|c|c|}
\hline \multicolumn{3}{|l|}{ Table 1: Sample characteristics } \\
\hline Characteristic & $M$ & Range \\
\hline Years experience in colorectal cancer care & 13.25 & $3-33$ \\
\hline Characteristic & \multicolumn{2}{|c|}{$\mathrm{N}$} \\
\hline \multicolumn{3}{|l|}{ Highest level of education } \\
\hline Bachelor & & 6 \\
\hline Master & & 2 \\
\hline \multicolumn{3}{|l|}{ Specialized oncology certification } \\
\hline Yes & & 2 \\
\hline No & & 6 \\
\hline \multicolumn{3}{|l|}{ Previous exposure to $O \mathrm{IN}^{\top M}$} \\
\hline Yes & & 1 \\
\hline No & & 7 \\
\hline \multicolumn{3}{|l|}{ Member of a speciality interest group } \\
\hline Yes & & 3 \\
\hline No & & 5 \\
\hline \multicolumn{3}{|l|}{ Participation in both $\mathrm{T} 1$ and $\mathrm{T} 2$ meetings } \\
\hline Yes & & 7 \\
\hline No & & 1 \\
\hline \multicolumn{3}{|l|}{ Note: $N=8$} \\
\hline
\end{tabular}

\section{METHOD}

\section{Design}

This study used a descriptive qualitative design with reliance on two moderated focus group discussions to obtain rich interactional descriptions (Loiselle, Profetto-McGrath, Polit, \& Beck, 2011; Sandelowski, 2000).

\section{Participants}

Eight participants were recruited, which included nurses licensed in the province of Quebec who had at least two years of colorectal cancer nursing experience and were directly involved in providing patient teaching and/or psychosocial interventions. Nurses who did not have internet access during work hours and were unwilling to participate in both focus groups were excluded. This study brought together general and specialist (e.g., radiotherapy, enterostomal therapy) nurses who had, on average, 13.25 years of experience in colorectal cancer care. Sample characteristics are presented in Table 1.

\section{Setting and procedures}

This study took place at a university-affiliated cancer centre in Montreal, Quebec. Scientific and ethics approval were obtained from the appropriate institutional boards.

Participants took part in two moderated focus groups (i.e., T1, N=8 and T2, N=7) separated by one month. During the one-month interval, they were provided with unrestricted access (i.e., web address, unique username, and password) to the English or French colorectal cancer title of the OIN ${ }^{\mathrm{TM}}$. Focus groups were held in a private room at the cancer centre at mutually convenient times during work hours. They were moderated by the senior author and data were collected using semi-structured interview guides. Field notes, including non-verbal and interactional data, were gathered by both authors during the focus groups (Duggleby, 2005). Discussions lasted between 60 and 75 minutes, were audio-recorded, and subsequently transcribed verbatim by the senior author. Participants were informed that individual follow-up interviews may be warranted for data verification.

\section{Data analysis}

Content analysis of the data was conducted based on methods by Morse and Field (1996) and Rabiee (2004). In applying the constant comparison method, notes on reactions and ideas that emerged while working with the transcripts were recorded throughout the analytic process (Loiselle et al., 2011). Data were coded based on emerging patterns, concepts, and themes. Assigned codes were reviewed and indexed into categories, from which descriptive statements were formed. Quotes were lifted from transcripts for rearrangement under the newly developed descriptive labels, allowing for comparisons within and between participant quotes. Resulting data were integrated and interpreted until consensus was reached among the researchers.

\section{FINDINGS}

Participants were active in both focus group discussions (i.e., at T1 and T2) with more spontaneous and highly interactive exchanges at T2. A collegial atmosphere prevailed in 
both meetings where nurses shared ideas, reflected together, and offered clarifications to each other's statements. Following exposure to the $\mathrm{OIN}^{\mathrm{TM}}$, a more focused exploration ensued of nurses' experiences and perceptions with this tool. Nurses reported varying comfort levels using connected health with consensus that tools such as the OIN ${ }^{\mathrm{TM}}$ should be integrated into modern nursing practice. Three main themes emerged: (a) key factors driving e-health use are multidimensional and evolving; (b) e-health platforms, such as the OIN ${ }^{\mathrm{TM}}$, are perceived as having the dual role of meeting patients and families' needs, as well as supporting nurses' work; and (c) e-health is a catalyst for professional development and networking. Each theme is reviewed in turn.

\section{Key factors driving e-health use are multidimensional and evolving}

Personal patterns of use. The nurses diverged in their propensity to access e-health resources in their professional roles. This difference was based on personal characteristics and preferences. One nurse said, "I'm old, so my first instinct is not to get onto the internet," whereas other nurses expressed that they often accessed a variety of e-health resources in their clinical practice. Some found that reading longer documents from a computer monitor was cumbersome and preferred printed materials. One said, "I need paper. ... If you send me a document [by email] that has more than two page[s], I'm gonna print it. I don't retain what I read on the screen." Others preferred electronic documents because they were "paperless" and more environmentally friendly. Diverging patterns of use also seemed to be related to experience and training. For example, several nurses, who were already familiar with electronic navigation in an educational or personal setting were more comfortable with adopting e-health in the hospital.

Efficient. In comparison to traditional reference books, e-health often allowed them to access professional information more efficiently. One nurse who preferred reference books compared herself to a colleague who preferred e-health, "You have a question in the office, and I'm headed to the library [for] books that we've got in our office and she's already plugged into the internet. Well, it's quite clear... [she] gets the [answer] first." In certain cases, it was easier to use internet search engines instead of reference books. When navigating e-health resources on the internet, nurses appreciated the fact that they could easily return to specific websites, like the OIN ${ }^{\mathrm{TM}}$. One nurse emphasized the need for simple navigation in e-health, "If it's got to do with a computer, and you want me on it, it's got to be simple, otherwise I'm hands off." Many were previously deterred by e-health tools that were too complex or abstract.

Reliable and relevant. To retrieve health information from the internet, some performed searches on broad search engines (e.g., Google, Google Scholar), whereas others returned to trusted scientific or medical information databases (e.g., UpToDate.com). There was group consensus that it was necessary "to be careful" and to critically assess the reliability and relevance of all e-health resources through multiple considerations, such as the quality of the sources, types of reviewers, and references. The nurses perceived expert-reviewed tools, like the $\mathrm{OIN}^{\mathrm{TM}}$, to be a reliable way to stay up to date with trends and evidence-based practices. They agreed that the information available through trustworthy e-health sources was "more recent [and] updated more" often than printed manuals. One nurse pointed out, "The books, they get old also, not only us."

Accessible in real-time. Nurses described current challenges they faced with intranet (in-hospital) medical documentation access, leading to inconsistent and incomplete patient information sharing. These access gaps were attributed to systemic factors, such as administrative lag, reliance on paper records, and incompatible software employed by different departments within the hospital. Despite these drawbacks, the nurses still saw e-health as a potential strategy to improve clinical practice and provide patient care by allowing real-time sharing of patient information between departments and hospitals. One nurse shared, "Well [let's] say ... that the patient [had] a problem in radiotherapy, then [at the bedside], we would know... what happened with him along the way... what he went through." This was underlined as an ideal process, especially because patients are increasingly receiving oncology care at more than one hospital.

E-health tools, such as the $\mathrm{OIN}^{\mathrm{TM}}$, are perceived as having the dual role of meeting patients' and families' needs as well as supporting nurses' work.

Increasing patient information availability. The internet made information more available to patients. E-health tools for patients, such as the OIN ${ }^{\mathrm{TM}}$, were interactive teaching options that could be customized to patient needs and information exchange styles (i.e., audio, visuals, video, text, printable format). Within the $\mathrm{OIN}^{\mathrm{TM}}$, the nurses appreciated the ability to search, sort, and display patient resources (e.g., sample questions to ask your physician/nurse, support groups) based on their needs (e.g., supportive, geographical location). This interactive and tailoring feature was a great way for patients to connect to relevant information and "find places where they can get help."

Ensuring quality materials for patients. To ensure content quality and appropriateness, the nurses emphasized the need to filter all the resources they gave to patients, including pamphlets, booklets, and e-health. The nurses offered numerous unprompted specific suggestions to improve the OIN ${ }^{\mathrm{TM}}$ for patients, including terminologies, descriptions, and navigational cues. Some nurses also suggested the addition of disclaimers to prompt patients to "check with their physician or nurse" before sections that detailed treatment plans that could vary across institutions. In discussing how these institutional differences could be better addressed in e-health tools, nurses began to reframe the discrepancies as teaching opportunities. One nurse shared:

"If there are some discrepanc[ies], you say [to the patient], '[Look], this is what they do'. There [are] many path [s] to go to Rome, as they say? ... There [are] different way[s] of doing things, but this is how we do it here." 
Saving energy and time for patients and nurses. E-health tools that are concise and comprehensive could potentially decrease patient stress levels. It was valued that e-health could guide and facilitate patient discussions on more sensitive and less-addressed topics, such as potential treatment side effects related to sexuality. One nurse commented that having this information available could reduce discomfort around the topic, allow the patient to process the sensitive material, and enable a more effective face-to-face nursing education session, "Which is good. The [OIN" $\left.{ }^{\mathrm{TM}}\right]$ talk[ed] about ... [treatments possibly] damaging the nerve and sexual function. So [if the patients read this privately] at least, [when] they come into our clinic... they are not [traumatized by the topic]." It was agreed that e-health could allow nurses to address some patient concerns faster and allow for more focused nurse-patient exchanges. Not only could e-health save time for the nurse, it could also save time and energy for the patient. By connecting to the patient verbally (i.e., by phone) and virtually (i.e., by internet, by emailing pictures), patients could have some issues resolved from home, potentially saving them from long commutes to the hospital and associated costs. One nurse explained:

I often use [pictures] with my patients!... They call, and they say, "I've got this weird thing on my stoma, can you uh [help]?'... Well, they live out in Hudson and [they] don't feel like driving all the way in, so I say, 'Oh so then take [a] picture!' ... and they email me the picture and I say, 'Oh, ok... I think you need to see me' or, 'No, I don't [need to see you]'.

By integrating a high-quality e-health resource as a teaching tool across institutions, the nurses saw a time and energy-saving opportunity to "give the same answers to patients" and improve patient guidance through more consistent care. This was especially important as many patients were now "crossing hospitals" and undergoing treatment at different centres. One nurse commented:

We need to... [as]similate the same type of information to unify [practice]. ... Because what happens is that our patients... will have the surgery here and their [other] treatment [there]. But some of them, they ha[ve] their surgery there or they are just coming [here] for their radiation. ... We need to make the link to facilitate [uniformity], we don't want another nurse to say different things [to a patient].

Reinforcing patient teaching and support. Some of the nurses were quite eager to have the $\mathrm{OIN}^{\mathrm{TM}}$, or a similar high-quality e-health tool available to patients. That being said, they clearly expressed that face-to-face interactions with patients were necessary. Nurses agreed that patients would still benefit from booklets, in-person teaching, hands-on demonstrations, and information sessions. E-health tools offered another way to reinforce patient teaching and provide support. The various presentation formats that e-health tools accommodated (i.e., print-outs, videos, interactive images) allowed patients to prepare for face-to-face teaching sessions and review interactive materials afterwards, at their own pace. One enterostomal therapy nurse said:
If you're talking about stomas, if there was like a link to ... a video of how to change a stoma... so when they get to us [for teaching], with [having seen] this [video], they're already ahead of the game.

\section{E-health as a catalyst for professional development and networking}

Acquiring professional knowledge through a complement of trusted resources. The nurses sought a mix of traditional and e-health resources to build their nursing knowledge. Traditional resources included reference books, written materials, and conversations with expert nurses. E-health resources included email correspondences with other healthcare professionals, webinars, online databases (academic and medical), and oncology association websites. Not surprisingly, nurses often returned to resources that worked in the past. One nurse shared:

There [are] things that I will not take what's on the internet.

[If] I know I read it somewhere... I'll go back to the book

'cause I know the answer in the book and I can trust that it's right.

However, it was agreed that because it was their professional responsibility to collect and disseminate evidence-based practices, e-health was an important channel for finding up-todate nursing resources.

Connecting with other health care professionals. Using complementary approaches (i.e., face-to-face, conference calls, e-mail, webinars, conferences) was the best way to build and coordinate professional connections. Although real-time conversations were considered best, the nurses agreed that e-health tools, notably email or online discussions, enabled an expanded reach, allowing them to connect to other nurses and professionals. For example, a nurse said, "I work a lot by word of mouth. So, we share a lot verbally, but... with [email], I can write to many (translated from French)". This advantage was particularly noted for nurses who were "not always easy to reach", such as evening or night nurses and professionals beyond their regular network. One nurse explained, "The links are very easy with colleagues [in the hospital] ... but it's at the level... [with the] internet, with the [OIN $\left.{ }^{\mathrm{TM}}\right]$ tool, I was thinking more about [linking with] colleagues outside of [our] hospital (translated from French)."

One nurse, who regularly connected with other nurses across the country shared how her sub-speciality special interest group used e-health to help create and maintain connections:

With our [group], we've done three, I think, four conference calls by phone. ... So first... it's all like emails of which dates [work] and who is available. And then... [the conference call] ... And then like the minutes are written by one person and then... [emailed] to everybody."

Exchanging information more interactively. It was agreed that information exchange through traditional methods and e-health channels were necessary to share and build professional knowledge. E-health was an opportunity to add another level of information exchange and interaction (i.e., video conferences vs. phone calls, online medical databases versus 
printed textbooks), especially within a group setting. Live conversations were still necessary to discuss and update patient care plans. However, in certain situations, email exchanges were perceived as a practical and complementary strategy to obtain the expertise of other health care professionals. One nurse described an experience in which she telephoned another health care professional regarding a patient's ostomy and the professional said, "Send me a picture", so the nurse took a digital picture and emailed it. Using e-health and traditional methods together, the health professionals were able to assess the ostomy together even though only one nurse was physically present with the patient.

Situating own practice in broader scope through common resources. The nurses saw that using e-health could provide an opportunity to assess their practices and to position themselves in a broader context (e.g., institutional, regional, national). This situating could be possible through the electronic sharing of protocols and standards of practice, which could help to reshape their own practice. One member of a national subspecialty special interest group shared, "With[in] the same specialty, ... if there's something that comes up in the clinic, I send an email out to the members and they'll send, you know, what they're using, their protocols, and suggestions."

Having a common e-health resource, such as the OIN ${ }^{\mathrm{TM}}$, available across different institutions was a way for nurses to "bounce back" ideas with more healthcare professionals. The nurses envisioned discussions through prompts such as, "What do think about this page?", "This is what it says-I was looking at doing that", and "What are others doing at other centres?" Discussions originating from a common e-health resource could help nurses "challenge" their practices and "challenge each other" to promote professional collaboration and advance practice.

The nurses discussed using e-health tools beyond their regular networks to consult and "use the experience of others" through special interest groups, such as Communities of Practice, which would bring together healthcare professionals with a common goal (i.e., colorectal cancer nursing care). Within a special interest group, discussion prompts (e.g., case studies, topics from a common e-health resource) could be used to create and guide opportunities for knowledge exchange. A member of a national nursing special interest group shared:

Even if you're just looking for help... you [email] a case study every now and then and you say, "This is what happened to us,' and everyone says, 'Well, you should [have] done this, or you could [have] done that'.

A special interest group was also a platform through which they could share and discuss relevant e-health. As one nurse said:

You know, like the article I saw on the business of drinking coffee that could... prevent the bowel ileus post op... I would have taken the opportunity [of a special interest group] to send it to all the nurses (translated from French).

\section{DISCUSSION}

Findings from this study are consistent with prior literature, whereby healthcare professionals perceive e-health tools as more efficient, timely, convenient, relevant, and accessible when compared to traditional methods (e.g., face-to-face) of clinical and professional development (Gilmour et al., 2016; Hesse et al., 2016; Klemp et al., 2011; Pilcher \& Bedford, 2011). Discussions highlighted the potential of e-health to improve current medical documentation integration within and across cancer care sites, echoing recommendations presented by the Institute of Medicine report on improving cancer care delivery (Institute of Medicine [U.S.], 2013). Although an earlier study found that nurses have limited skills and encounter difficulties when searching for relevant virtual information (Verhoeven et al., 2010), the current study suggests, instead, that nurses employ unique patterns of e-health usage to retrieve information. These patterns are based on personal experience, confidence, and preferences for certain electronic resources or formats, a trend that is supported by more recent studies (Chiu \& Tsai, 2014; Hains et al., 2012; Jones et al., 2011; Maggio, Steinberg, Moorhead, O’Brien, \& Willinsky, 2013). The current study results emphasize that e-health cannot entirely replace traditional methods of professional learning and information exchange but, instead, are most beneficial when used as a complement to existing resources.

A survey conducted in 2003 revealed that $91 \%$ of oncology healthcare professionals perceived internet-retrieved information as harmful to patients (Newnham et al., 2005), whereas a survey 10 years later showed a shift in attitudes, with 57\% of oncology healthcare professionals recognizing that internetretrieved information could add value to patient care (Emond et al., 2013). This trend is echoed by Haase and Loiselle (2012), who reported that nurses perceive certain e-health tools to be high-quality with the potential to enhance nurse-patient education, communication, and trust. Findings from this study also suggest that oncology nurse perceptions towards e-health continue to shift positively, for both nurse- and patient-focused applications.

Similar to another Canadian study by Lemonde and Payman (2015), participants herein discussed how they are confronted with increasingly complex cases. Patients are often seen by various medical specialists and hospitals. Providing consistent care, information, and support to such patients is particularly challenging. Nurses in this study suggest that e-health is a viable strategy that can enable more continuity in care while also providing a platform for professional development. If well integrated, e-health is a crucial complementary means to maintain professional connections, opportunities, and collaborations (i.e., via special interest groups) with colleagues within and outside of their own institutions. In fact, integrating e-health resources within special interest groups (e.g., communities of practice) has yielded positive results in healthcare (Farrell, La Porta, Gallagher, Vinson, \& Bernal, 2014; Ranmuthugala et al., 2011). This study supports the connective and interactive potential of e-health to further propel the development of such special interest groups in oncology nursing. 


\section{Limitations}

The findings should be viewed in light of some limitations such as reliance on a homogenous sample of advanced practice and specialist oncology nurses (with underrepresentation of ambulatory and bedside nurses), as well as being in the context of one type of diagnosis: colorectal cancer. Additionally, participants were given access to the OIN ${ }^{\mathrm{TM}}$ for four weeks, which may not have been sufficient for them to fully appreciate the platform's potential.

\section{Future directions}

As the connective potential of e-health was emphasized by nurses in this study, it will be worthwhile to examine emerging virtual professional and social networking platforms that can connect more stakeholders simultaneously and in different ways (i.e., nurses, patients, other healthcare professionals). Equally important is to more fully document integration and user experiences, as connected health technology becomes

\section{REFERENCES}

Bakker, D., Strickland, J., Macdonald, C., Butler, L., Fitch, M., Olson, K., \& Cummings, G. (2013). The context of oncology nursing practice: An integrative review. Cancer Nursing, 36(1), 72-88. doi:10.1097/NCC.0b013e31824afadf

Chiu, Y.L., \& Tsai, C.C. (2014). The roles of social factor and internet self-efficacy in nurses' web-based continuing learning. Nurse Education Today, 34(3), 446-450. doi:10.1016/j.nedt.2013.04.013

Dubois, S., \& Loiselle, C. (2008). Understanding the role of cancer informational support in relation to health care service use among newly diagnosed individuals. Canadian Oncology Nursing Journal, 18(4), 193-205.

Duggleby, W. (2005). What about focus group interaction data? Qualitative Health Research, 15(6), 832-840. doi:10.1177/1049732304273916

Emond, Y., de Groot, J., Wetzels, W., \& van Osch, L. (2013). Internet guidance in oncology practice: Determinants of health professionals' Internet referral behavior. Psychooncology, 22(1), 74-82. doi:10.1002/pon.2056

Farrell, M.M., La Porta, M., Gallagher, A., Vinson, C., \& Bernal, S.B. (2014). Research to reality: Moving evidence into practice through an online community of practice. Preventing Chronic Disease, 11, E78. doi:10.5888/pcd11.130272

Gilmour, J., Strong, A., Chan, H., Hanna, S., \& Huntington, A. (2016). Primary health-care nurses and Internet health informationseeking: Access, barriers and quality checks. International Journal of Nursing Practice, 22(1), 53-60. doi:10.1111/ijn.12361

Haase, K.R., \& Loiselle, C.G. (2012). Oncology team members' perceptions of a virtual navigation tool for cancer patients. International Journal of Medical Informatics, 81(6), 395-403. doi:10.1016/j.ijmedinf.2011.11.001

Hains, I.M., Ward, R.L., \& Pearson, S.A. (2012). Implementing a webbased oncology protocol system in Australia: Evaluation of the first 3 years of operation. Internal Medicine Journal, 42(1), 57-64. doi:10.1111/j.1445-5994.2010.02284.x

Hauffman, A., Alfonsson, S., Mattsson, S., Forslund, M., Bill-Axelson, A., Nygren, P., \& Johansson, B. (2016). The development of a nurse-led internet-based learning and self-care program for cancer patients with symptoms of anxiety and depression-A part of U-CARE. Cancer Nursing. doi:10.1097/NCC.0000000000000402 increasingly sophisticated and multifaceted in the forms of patient-clinician portals, wearables, and other personalized mobile health applications.

\section{ACKNOWLEDGEMENTS}

The authors wish to acknowledge Dr. Margaret Purden from the Ingram School of Nursing, McGill University, Ms. Jacqueline Vachon, and Ms. Saima Ahmed for their thoughtful comments and insights in earlier versions of the manuscript. The authors would like to thank oncology staff who facilitated recruitment of participants and the oncology nurses who generously and thoughtfully discussed the issues at hand.

This study was supported, in part, by a fellowship from the Canadian Institutes of Health Research (CIHR) Psychosocial Oncology Research Training (PORT) Program and a bursary from the Ministère de l'Éducation, du Loisir et du Sport (MELS) du Québec.

Hesse, B.W., Greenberg, A.J., \& Rutten, L.J. (2016). The role of Internet resources in clinical oncology: Promises and challenges. Nature Reviews Clinical Oncology, 13(12), 767-776. doi:10.1038/ nrclinonc. 2016.78

Institute of Medicine (U.S.). (2013). Delivering high-quality cancer care: Charting a new course for a system in crisis. Washington, DC: The National Academies Press.

Jones, J., Schilling, K., \& Pesut, D. (2011). Barriers and benefits associated with nurses' information seeking related to patient education needs on clinical nursing units. The Open Nursing Journal, 5, 24-30. doi:10.2174/1874434601105010024

Kaltenbaugh, D.J., Klem, M.L., Hu, L., Turi, E., Haines, A.J., \& Hagerty Lingler, J. (2015). Using web-based interventions to support caregivers of patients with cancer: A systematic review. Oncology Nursing Forum, 42(2), 156-164. doi:10.1188/15.ONF.156-164

Klemp, J.R., Frazier, L.M., Glennon, C., Trunecek, J., \& Irwin, M. (2011). Improving cancer survivorship care: Oncology nurses' educational needs and preferred methods of learning. Journal of Cancer Education, 26(2), 234-242. doi:10.1007/s13187-011-0193-3

Lemonde, M., \& Payman, N. (2015). Perceived roles of oncology nursing. Canadian Oncology Nursing Journal, 25(4), 422-442.

Loiselle, C.G., Edgar, L., Batist, G., Lu, J., \& Lauzier, S. (2010). The impact of a multimedia informational intervention on psychosocial adjustment among individuals with newly diagnosed breast or prostate cancer: A feasibility study. Patient Education and Counseling, 80(1), 48-55. doi:10.1016/j.pec.2009.09.026

Loiselle, C.G., Peters, O., Haase, K.R., Girouard, L., Korner, A., Wiljer, D., \& Fitch, M. (2013). Virtual navigation in colorectal cancer and melanoma: An exploration of patients' views. Supportive Care in Cancer, 21(8), 2289-2296. doi:10.1007/s00520-013-1771-1

Loiselle, C.G., Profetto-McGrath, J., Polit, D.F., \& Beck, C.T. (2011). Canadian essentials of nursing research (3rd ed.). Philadelphia: Wolters Kluwer Health/Lippincott Williams \& Wilkins.

Maggio, L.A., Steinberg, R.M., Moorhead, L., O’Brien, B., \& Willinsky, J. (2013). Access of primary and secondary literature by health personnel in an academic health center: Implications for open access. Journal of the Medical Library Association, 101(3), 205-212. doi:10.3163/1536-5050.101.3.010 
Morse, J.M., \& Field, P.-A. (1996). Nursing Research: The Application of Qualitative Approaches (2nd ed.). United Kingdom: Nelson Thornes.

Moule, P., Pollard, K., Armoogum, J., \& Messer, S. (2015). Virtual patients: Development in cancer nursing education. Nurse Education Today, 35(7), 875-880. doi:10.1016/j.nedt.2015.02.009

Newnham, G.M., Burns, W.I., Snyder, R.D., Dowling, A.J., Ranieri, N.F., Gray, E.L., \& McLachlan, S.A. (2005). Attitudes of oncology health professionals to information from the Internet and other media. The Medical Journal of Australia, 183(4), 197-200.

Pilcher, J.W., \& Bedford, L. (2011). Willingness and preferences of nurses related to learning with technology. Journal for Nurses in Staff Development, 27(3), E10-16; quiz E17-18. doi:10.1097/ NND.0b013e318217b447

Rabiee, F. (2004). Focus-group interview and data analysis. Proceedings of the Nutrition Society, 63(04), 655-660. doi:10.1079/PNS2004399

Ranmuthugala, G., Plumb, J.J., Cunningham, F.C., Georgiou, A., Westbrook, J.I., \& Braithwaite, J. (2011). How and why are communities of practice established in the healthcare sector? A systematic review of the literature. BMC Health Serv Res, 11, 273. doi:10.1186/1472-6963-11-273

Rennie, H., \& Mackenzie, G. (2010). The psychosocial oncology learning assessment: A province-wide survey of cancer care providers' learning needs. Journal of Cancer Education, 25(2), 206210. doi:10.1007/s13187-010-0112-z

Sandelowski, M. (2000). Whatever happened to qualitative description? Research in Nursing a Health, 23(4), 334-340. doi:10.1002/1098-240x(200008)23:4<334::aid-nur9>3.0.co;2-g
Santos, M.C. (2012). Nurses' barriers to learning: an integrative review. Journal for Nurses in Staff Development, 28(4), 182-185. doi:10.1097/NND.0b013e31825dfb60

Schweitzer, D.J., \& Krassa, T.J. (2010). Deterrents to nurses' participation in continuing professional development: An integrative literature review. Journal of Continuing Education in Nursing, 41(10), 441-447; quiz 448-449. doi:10.3928/00220124-20100601-05

Townsend, A., Leese, J., Adam, P., McDonald, M., Li, L.C., Kerr, S., \& Backman, C.L. (2015). eHealth, participatory medicine, and ethical care: A focus group study of patients' and health care providers' use of health-related Internet information. Journal of Medical Internet Research, 17(6), e155. doi:10.2196/jmir.3792

Vedel, I., Lapointe, L., Lussier, M.T., Richard, C., Goudreau, J., Lalonde, L., \& Turcotte, A. (2012). Healthcare professionals' adoption and use of a clinical information system (CIS) in primary care: Insights from the Da Vinci study. International Journal of Medical Informatics, 81(2), 73-87. doi:10.1016/j.ijmedinf.2011.11.002

Verhoeven, F., Steehouder, M.F., Hendrix, R.M., \& van GemertPijnen, J.E. (2010). How nurses seek and evaluate clinical guidelines on the Internet. Journal of Advanced Nursing, 66(1), 114127. doi:10.1111/j.1365-2648.2009.05175.x

Younger, P. (2010). Internet-based information-seeking behaviour amongst doctors and nurses: A short review of the literature. Health Information and Libraries Journal, 27(1), 2-10. doi:10.1111/j.1471-1842.2010.00883.x 